\title{
THE POSSIBILITIES AND IMPORTANCE OF EDUCATING THE DENTIST THRU ORGANIZATION.
}

\author{
By E. R. Swank, D.D. S., Des Moines, Iowa.
}

(Read before the National Dental Association at Its Twenty-third Annual Session, New Orleans, La., October 20-24, 1919.)

$\mathrm{D}$ ENTISTRY, quite as much as any of the specialties of medicine, is logically a branch of general medicine. Traditions and circumstances attending the birth of dentistry, have long separated the two professions, and have operated against public welfare, preventing recognition of this fundamental fact. In the light of our present-day knowledge, it is obvious to students of both sciences, that neither can render its highest service to the individual in the interest of public health, unless some means of post-graduate education is carried on that enables the older practitioners to keep pace with the rapid advance of the sciences, and that furthermore forms a bond of understanding and cooperation uniting them into closer fellowship.

The foundation for our professional education is being gradually broadened, and the pre-requisites of its applicants are also becoming more rigid thru the raising of the standard of requirements, and results demanded by our Dental Colleges and Dental Examining Boards, thru the splendid and untiring work of the Dental Educational Council of America. This is as it should be, but this alone is not sufficient. The college graduate, after he has received his diploma, has yet a long way to travel, and our profession demands of every man that he be not self-satisfied with the education that he acquired in college, but that he become a "researcher" and delve into the problems of our profession and by his unselfish and untiring effort, enrich it and maintain it on a parity with medicine, our mother profession.

Cooperation is the secret of most successes. The lack of cooperation is the cause of many failures and egotism is a germ that inhibits cooperation in our professional societies. "No man can stand alone in life, or work alone in a business or profession and at the same time obtain for himself the same rewards, money, influence and happiness, as when he works with and by and thru the organization and the social body of which he is a part." This law is inexorable. All great battles of the recent war were planned and executed thru organization, and system. All great business enterprises are carried on according to the same law, and no less is the success of our Dental Institutions dependable upon this same fundamental fact. No river ever rises higher than its source and no Dental Society will ever grow beyond the spirit and aim of its executives. If a man thinks in penny values, he will deal in pennies and peanuts, but if he thinks in five or seven figures, he will deal in larger resources and enterprises. There are no accidental successes in the business world. Luck, or rather chance, may seem to play a part in placing a man in a favorable position, but luck does not keep him there. Thus preparedness is a 
fundamental pre-requisite to success and I leave it for you to know that the dentists of tomorrow, who will lead our profession, are the men of today who are earnestly and diligently delving into and studying out and grasping the knowledge that is essential to the leadership they will hold.

The greatest problem of the Dental Societies today, lies not so much in finding new operative procedures or new methods of practicing our profession, as in keeping the majority of the profession abreast of the progress already achieved. It is not by the prominence or ability of a few men who stand out, as it were, as stars in a night, that set the standard for our profession, but it is the great body of men in the little towns and villages that make the average and regulate the caliber of the professional standard. It is this body of men we must look forward to helping and it is their problems we must solve.

The Dental Colleges and Dental Journals are important factors in our progress, but we cannot deny the fact that the masses of our profession are moved forward thru the work of the local district and State Dental Societies. The Dental College is the principal force in the early and formative period of a dentist's career. The Journals serve him in advising him of the new things of his profession and the scientific progress made, but the society is the source of his real advancement by fact of its power to teach him first hand and by word of mouth, as he was taught in college, and allowing him to rub shoulders with his fellow-man and receive his viewpoint.

Since childhood, we have been taught in our schools by certain methods of study and training, to grasp and assimilate certain facts which then become our property and our knowledge. In our dental colleges the same system of procedure is practiced. In our Dental Societies it is not. What is the result? Simply this, only as our Dental Societies arrange, plan and execute a program along a teaching line do they measure up to and hold the attention of their constituent body.

We have in our profession, three classes or types of dentists, the successes, the mediocrities and the failures. The successes are always open-minded, receptive and willing to grasp new facts from any source open to them and at any and all times. The mediocrities are not so receptive to new ideas and are very careful not to accept new things until after they have become the generally recognized practice of the profession at large and are demanded of them by their clientele. They are not trail-blazers, but are followers. They lack the initiative of leadership, are always raising the question of doubt and are never sure of themselves. They are afraid to assert an opinion for fear of criticism and the same fear keeps them from giving clinics, reading papers and taking any active part in society work. The last class are the failures who lack even the initiative to follow. They are the men who have chosen a wrong path in life and sooner or later drop by the wayside.

By what standard are we to measure an organization that is to meet the requirements of our day? Not by the standard or by the methods of conducting our society meetings of fifteen years ago, or even five years ago. Conditions have changed and we must change with them.

A close study of conditions in Iowa, (and I think it is representative of most other states) reveals the fact that approximately $25 \%$ of our profession is practicing in the city and $75 \%$ in the country. The city man has every opportunity for keen competition. By every reason of competition he is spurred on to keener study, to more accurate work and a fuller and broader knowledge of his profession. $\mathrm{He}$ is able to join himself with other men in the formation of study clubs that further 
develop him and solve his problems. The isolated country dentist has no such opportunity afforded. The problem of reaching this man is of prime importance and is essential to raising the standard of the dental profession as a whole. $\mathrm{He}$ is generally the man in the mediocre class and to him the Dental Societies should look forward to helping. There is but one way in which this man can keep pace with progress; that is thru continued application and the study of his profession thru Societies, Study Clubs and Dental Journals.

System is the key that unlocks the door of efficiency and success. A large manufacturing plant such as produces the Ford automobile for example, has a central head. Radiating from this head are sub-heads or Superintendents of Departments. Each department is further sub-divided according to its needs ad infinitum. In the dental world we have the N.D. A. as a head. Its components, or sub-heads, are the State Societies, further sub-divided into district or local societies, and in the district and local societies, we should find the real spring of knowledge in the study clubs.

But is the N.D.A. a real head, and does it exercise proper supervision over its component State Societies? Then also, are all our State Societies conducted and promoted along practically the same lines? Are all State Societies subdivided into District Societies which are component parts and under direction of the Superintendent of District Societies? Does the State Society or the District Society have smaller bodies or study clubs within their jurisdiction?

In an effort to help answer these questions, I prepared a questionnaire which was sent to the secretary of every State Dental Society and to the deans of all our Dental Colleges. I tried to secure an expression from these sources, of the organization and methods of conducting the State Societies and their attitude in regard to Post-Graduate work. The following were the questions asked the Secretaries of State Societies:

1. How many dentists practising in your state (approximately)?

2. How many are members of your State Society?

3. Is your state divided into District Societies? If so, how many? Are they components of your State Society?

4. Do you have a Superintendent of Districts who endeavors to coordinate the work of the District and State Societies?

5. Is your executive committee appointed or elected?

6. Who selects talent and clinicians for your meetings? By what particular method?

7. Does your State Society give a so-called Post-Graduate course at its meetings? What plan do you follow?

8. What is the average attendance of your state meetings?

9. How many study clubs have you thruout your state? (Approx.)

10. Would you think it advisable for a committee from the N. D. A. to assist Study Clubs and report on the results attained by them?

11. Do you approve of individuals establishing Post-Graduate schools along the lines of their specialties?

12. Do you favor Dental Colleges establishing Post-Graduate courses, using the same teaching staff for academic and Post-Graduate work?

13. Would you think it a good plan to have a Superintendent of State and District Societies in the N. D. A. who would keep on file a list of available clinics and clinicians and otherwise assist the State and District Societies in planning their programs and Study Clubs?

The following were the questions asked the Deans of our Dental Colleges:

1. What was your student enrollment for 1918-1919? 
2. Do you offer a Post-Graduate course?

3. Do you grant a degree for PostGraduate work?

4. What recognition, if any, is given for successfully completing the course?

5. Is the Post-Graduate work given by the regular staff?

6. What is the Post-Graduate enrollment?

7. Is the course open to students during their Senior year?

8. How many courses do you give? What time of year are they given? Of what do they consist?

9. Are the classes filled to capacity?

10. How long are the courses?

11. What is the professional attitude toward Post-Graduate work? Remarks.

12. Do you think State Dental Societies should offer Post-Graduate courses? Remarks.

13. Do you think it advisable for individuals to offer so-called PostGraduate courses along the lines of their specialty?

14. In your opinion, briefly, what is the best method of handling the problems of keeping the Dental Practitioner educated up to the minute in the advances of Dental Science?

15. Are senior students given an opportunity to receive special instructions and inspiration by individuals who are especially successful in their specialties?

I shall not attempt in the time allowed me for this paper to discuss the results of each question separately, but will summarize as a whole the answers given.

The number of dentists practicing in a state varies from 75 to 5,500 . I found in one state $100 \%$ of all eligible dentists members of the society. In others I found less than $20 \%$ were members. An average nembership of State Societies shows approximately $45 \%$ of practicing dentists members of societies. Fifty-two per cent of the State Societies are divided into districts. To my mind the larger a body without sub-divisions, the more unwieldy and unsatisfactory is its work. Sub-division of State Societies into component districts, coordinated under direct supervision of one head or committee, will work better and more efficiently. I found $81 \%$ of our societies without such a superintendent or committee.

In regard to the selection of talent, no particular method has been adopted, but almost any haphazard way of selecting such clinicians and essayists as can be secured, without much real thought apparently as to any certain program, procedure or subject to be presented at a particular meeting. No system is followed in conducting their meetings and no goal is set toward which they are aiming. Is not this one reason why only $45 \%$ of the dentists of our country belong to societies? Is the society living up to its possibilities, organizing and commanding attention, solving the problems and educating the dentist as it might? The Dental Society must become a real educational center for the dental practitioner. It is in reality a post-graduate school, and until such time as our dental colleges meet this requirement for advanced education, our State Societies must assume this responsibility.

From the replies I received, eighteen societies have made an attempt of postgraduate work. However, $50 \%$ qualified their answers by saying no special system had been followed and, in some cases, they had abandoned the course entirely as it was not conducted in such a manner as to meet popular approval of the membership. In two states only did I find a real effort of organized and systematized plans to conduct postgraduate work. These societies were divided into classes with a competent instructor over each subject and the school was formed along collegiate lines. However, a student was permitted to enter 
but one class at this session. Thus the instructors were assured full attendance to classes, and the student was enabled to learn and assimilate his subject in a way that proved satisfactory and beneficial.

The question as to the number of study clubs in a state was exceedingly surprising. I found only forty-nine clubs in the whole country, twenty State Secretaries did not know of any clubs within their state at all. Self-satisfaction is a germ that inhibits initiative and progress and is the cause of much of the indifference to study clubs and society work. Success is attained only by application and diligent study. The minute a man in his own mind becomes satisfied with his position in the affairs of life, his professional, social or financial place, that minute he begins to go backward. Progress is forward, never backward. Apathy in the matter of Study Clubs in the dental profession, is the cause of mediocracy. Until we wake up and realize the importance of the place Study Clubs must have in our professional work, we will never be able to raise our standard.

The question relating to the attendance at State and District meetings, was very disappointing. According to figures given, not $40 \%$ of our society membership attend their State meetings and not $25 \%$ attend their District meetings. Carried a little further this means but slightly over $10 \%$ of the dental profession attend their society, sessions. This thought will bear repeating, that our societies never rise higher in efficiency in holding attention of their membership than the aim and spirit of their executives. Are we selecting the right men for the right places and do we keep efficient men in the harness, or do we believe in passing the honor around to the detriment and loss of the society as a whole? An efficient industrial plant does not annually pass the honor of Superintendent or Departmental head around among' its various employees. Neither should an efficient dental organization pass the working offices, such as the Executive Committee, Superintendent of clinics or Program Committee, or Executive Council of District Societies among new men every year. Provision should be made to keep officers of this sort in office a term of years, rotating the officers by districts and years, in order to maintain experienced men to efficiently manage the affairs of the organization. Such provision is not maintained for long enough periods in most of our State Societies and is another cause of lack of efficiency. Airships do not rise from the ground and fly if too heavily ballasted. Neither will our Dental Societies fulfill their possibilities and mission in the world if manned by too many inexperienced officers. They constitute too much ballast and should be discarded and a reorganization made.

Three methods of procedure are now in vogue in conducting post-graduate work. (1) Short courses known as extension courses are available upon a few subjects in some three or four of our Dental Colleges. (2) Individuals especially proficient in certain specialties of their professional work, conduct small classes in various sections of the country under the so-called cognomen of postgraduate schools. The third method is for State Societies to conduct their meetings along post-graduate school lines. There are advantages and disadvantages to be found at present, in any one of these methods.

The approval of individuals establishing post-graduate schools along the lines of their specialties was given by nineteen out of thirty-five State Society officers and disapproved by sixteen. And from the reports of thirty-two out of forty-six deans answering this same question, twenty were not in favor of individuals establishing pöst-graduate courses along lines of their specialties, and eight qualified their answers of ap- 
proval, provided the individual was especially fitted and equipped to teach his subject, leaving four who gave no answer.

Answers from thirty State Society officers to the question, "Do you favor Dental Colleges establishing post-graduate courses, using the same teaching staff for academic and post-graduate work?" resulted in thirty affirmative answers for colleges establishing postgraduate courses, but were variable as to the advisability of using the same teaching staff, with twenty favoring the use of such a staff. Ten were unqualifiedly opposed to using the same staff. From the reports of the Deans of Dental Colleges on this same question, I found that most of them, until such time as the colleges are able to establish regular postgraduate work, are in favor of the Dental Societies giving short post-graduate courses, but they feel that in order to obtain the best results with competent teachers and proper teaching facilities, it is a problem for the Dental Colleges to solve and not for the State Societies.

I found an almost unanimous opinion that post-graduate work was essential to a dental practitioner if he is to keep pace with the progress of his profession. Study courses in societies under the leadership of competent instructors offer only a temporary solution and should be so considered in the conduct of societies. Such courses are necessarily intensive but do not take the place of good post-graduate work.

The deans were also asked the following question: "Do you think Dental societies should offer post-graduate courses?" The following is one of the answers:

"I think the country should be divided into educational centers for post-graduate work and that the University schools in these centers should give the courses under the direction of an educational committee of experienced teachers. These courses should be in full accord with the
State Societies and the schools should run independently of the regular college instructions. The teaching faculty should be composed of the best men obtainable in the branches taught."

A quotation from the dean of one of our largest dental schools says: "If under-graduate colleges are to institute post-graduate courses, a separate faculty of specialists should be employed. The interference of special courses with regular under-graduate work should not be considered. Post-graduate school as a separate institution would be the better arrangement, but it will be years before this is brought about. A post-graduate course should lead to a Post Graduate degree and should require from one to two years attendance; with a definite curriculum, short courses to be called special courses, not post-graduate courses, credit to be allowed for each course, depending on time and subject. To illustrate, one credit for two weeks course; two for four weeks. When the practitioner has attended a sufficient number of special courses to receive eighteen credits, a post-graduate degree may be applied for, Doctor or Master of Dental Science. If special courses are to be of worth, a definite requirement should be stated."

The majority of the deans are giving serious and earnest thought to this question and from the discussions in the meetings of the Dental Faculties Association of American Universities and the National Association of Dental Faculties, we may, in a measure, look forward to the solution. However, only as the individual dental practitioner demands of our colleges and our societies establishments of definite requirements, will we be able to deal in a satisfactory and decisive manner and hope for its final solution. And this is not all, for at the present time we have in our country, Dental Examining Boards whose ideals are not as high as they might be, that are lax in their duties, and men of a 
type who never reach above the mediocre class and often fall in the class of failures, are permitted to pass thru and become licensed. Until the time comes that the recommendation made by Doctor Logan in his President's address at Chicago last session, establishing a uniform and standard National Dental Examining Board is a fact, will we begin to solve this problem and the scales will fall from the eyes of those responsible for our dental curriculum and for the program of our Dental Societies.

The final solution of the post-graduate problem must come from three bodies formed by the Dental Colleges, Dental Societies and Dental Examining Boards. Thru the national organizations of these bodies will come discussions, plans, ideas, and recommendations that will eventually bring about the ultimate triumphant solution. This is the goal toward which we must work with a unity of purpose and cooperation with one another.

With the thought in mind of coordinating, standardizing and making easier the work of State Societies, I asked the State Societies the following question: "Would you think it a good plan to have a Superintendent of State and District Societies in the National Dental Association who would keep on file a list of available clinics and clinicians and otherwise assist the State and District Societies in planning their program and study clubs?" Thirty-six answers out of thirty-eight were affirmative, with but two negative.

From the above evidence submitted from the Secretaries of State Societies and Deans of Dental Colleges, I wish to draw some conclusions and outline some definite, reasonable possibilities for improvements as I see them in our present dental organizations.

1st. "At present we are not living up to our obligations and possibilites in either our Dental Societies or our Dental Colleges." 2nd. "Post-graduate work is a problem for the Colleges and not the State Societies." Teachers in our public schools have colleges in which to train in order to be able to secure for themselves higher education. In turn the college professors have post-graduate schools in our larger Universities that are endowed with special funds and equipment for purposes of higher research work that is essential for their further advancement. The same is true of the medical profession. They have the large hospitals where they can go, and beyond these such large endowed foundations for medical research as the Rockefeller Institute and the Mayo Brothers Institute at Rochester, Minn. The Dental Profession has no such higher educational advantages, and it is evident such institutions as our medical brothers are privileged to maintain, give them an unlimited field for developments and are so organized and controlled that they give recognition and authority to the opinions and technical procedure of specialists in certain branches of their profession.

The dental practitioner goes thru an under-graduate Dental College, but if he wishes to further specialize along a particular line, he has nowhere to go unless to a so-called post-graduate school conducted by private individuals for private gain where he pays a high fee and does not come out with a properly recognized certificate showing he has fulfilled prescribed requirements of a definite nature, and recognized by sovereign laws of his State in the same manner as is granted under-graduate schools. This is a need the dental profession is facing and should be agitated so strongly that our Dental Colleges will become impressed with its importance and make plans and take steps to meet it by establishing separate post-graduate schools in their colleges. But three or four of our colleges at present have made an attempt to establish post-graduate work of this kind and then it was in the 
nature of an experiment with short courses. The results, however, have fulfilled their expectancy and they are laying larger and broader plans for extension of the work.

3rd. "The Dental Colleges should establish separate faculties of specialists for post-graduate work with a curriculum of definite requirements leading to a Master of Dental Science degree." Only as we labor toward a goal do we accomplish desired results. As a man enters his freshman year in college, he looks forward over the span from the first to the last day, four years in the future, and in his heart wells up that great overwhelming desire to reach that day. The trials, the pit-falls and discouragements that he must bear and overcome, serve to further his ambition to keep his face steadily to the front and reach this goal. But how about the man in practice, who comes to the point that he feels the very urgent need of higher education along certain of his professional lines? He feels this need but where can he turn and enter a post-graduate school and pursue a prescribed course of study that will satisfy him and equip him to meet the demands he has in mind? He is groping for certain knowledge and it is furthermore true, he is also in search of certain honors or recognition for the labor and work he has accomplished. He will work harder, steadier and longer, if need be, for such an honor or recognition and it is for our dental colleges to take the next step with him and provide an institution meeting the demand and granting a degree commensurate with the place it occupies in the field of higher education. The degrees of Doctor of Philosophy, Doctor of Divinity, and Doctor of Science, are granted only in recognition of work done beyond that of the under-graduate college and the subjects leading to such degrees are taught by separate staffs in our larger Universities and constitute post-graduate college work. Special equipment for research work is provided in these institutions, and in many instances, fellowships are available for men pursuing such work. Thus incentive for advanced work is before a man and the earnest man is given every opportunity to proceed with his ambition. From the ambition of men come the great things of this world and also the advances. Every possible means should, therefore, be given for progress and this is as applicable in the dental profession as in any other line of human endeavor.

4th. "Dental Societies should limit their activities to coordinating isolated efforts and encouraging clinics, essays and research work by individuals and opening its sessions as a Forum for discussion of the practical and everyday problems confronting its members." The State Dental Society should be an experimental laboratory in order to carry out this plan. It is here, home talent should be developed and new ideas given a try-out. It is here that men with their coats off and sleeves rolled up come shoulder to shoulder and thrash out the little things that are constantly arising in practice. It is here that papers are read and new theories propounded and discussed. It is here that new procedures and new instruments for handling the same should be exhibited. This is the logical place for such things and the society should not enter the field of post-graduate work, for they lack equipment, time and facilities for handling the classes. Attention at such meetings cannot be successfully concentrated, as it necessarily must conduct diversified subjects under conditions not permanent and often handicapped in many ways that distract the mind of its members. Then too, and this is a fact not to be lost sight of ; many members attend their society meetings for the reunion of friendships and acquaintances of college days, and this is a tie that binds them together as a society. It is this feature that is as uppermost in their minds as 
any other and is absent when attending regular post-graduate work in some ininstitution, as they are then strictly business, and are willing to sacrifice time, pleasure and money for the ends they are working toward.

5th. "Elimination of all so-called post-graduate schools and courses conducted by men along lines of their specialties, but such men of merit should be affiliated with post-graduate departments of colleges where just and due recognition is given both to themselves and their work." Thus commercialized post-graduate courses are eliminated and real professional advancement is attained and granted upon a practical and deserving basis. These men by the peculiar fitness they possess are logically the proper men to become teachers of their lines, and the recognition of these men in the faculties of post-graduate schools, will work benefits two-fold; first, for the individual by recognizing his ability and work by law governing postgraduate dental schools as it governs under-graduate schools; and secondly, giving added prestige to the Dental College and raising it to a higher standard of usefulness. Dentists of ability who today are striving by their own efforts to teach a certain thing and are conscientiously endeavoring to promote and raise the professional standard will have their efforts coordinated and recognized and the task before them will find easier and quicker solution. Elimination in this manner does not work a hardship upon an individual except in rare instances where personal greed enters, and such elimination purifies the profession as a natural and beneficial consequence, self-adjusting in most cases in its action.

6th. "Provision should be made in the N.D.A. for a superintendent of State Dental Societies that will coordinate their work and purposes and strengthen and unify these organizations, and incidentally give added strength to the N. D. A. by such supervision." Under direction of the Board of Trustees or House of Delegates, provision should be made for an assistant secretary of the N. D. A. called "The Superintendent of State Dental Societies" or some other suitable title or office, whose duties will be to coordinate the efforts of the various state societies and systematize and establish efficiency within their organizations. Much lost motion in time, effort and selecting good talent is now present in our work. This lost motion should be turned to useful account, for example, it happens as often as not that good talent is available for certain subjects nearer the home of a society than that which they employ. Here a saving in expense to the society can be made, also an individual worthy of teaching a subject is recognized and employed, thus mutually benefiting both parties. It should be his further duty to keep on file a list of available clinics, clinicians and essayists for reference and use of the state society officers in outlining, planning and arranging their program. Talent will also avail themselves of this privilege of "listing" their work with him and thus a double purpose is accomplished thru this medium with a minimum expenditure of time and effort on the part of society officers and talent. He could arrange itineraries for talent that would be advantageous as expenses of long journeys could be cut down and absence from office practice could be arranged conveniently for clinician enabling him to appear before more societies at a less fee per society.

The advantage of such an officer in the N.D. A. would be of great importance not only as I have indicated, but in other avenues that would open up and that work for service, system and efficiency, which is the paramount obligation of this organization.

Under direction of each state society, a committee would be formed promoting and having supervision over Study Clubs and further coordinating this work by 
supervisory direction under the superintendent of State Dental Societies of the N. D. A., thus giving the national body a voice in helping outline study courses, regulate their activities, receive and approve researches made and the work done by such clubs. Several articles have appeared in our Dental Journals of late in regard to this phase of our educational work. Its importance is recognized and should be encouraged. Small bodies of men, conveniently located, banded together in a congenial club, all interested in some particular subject of their work, can do most valuable research work and equip themselves to meet their problems in a simplified and efficient manner. In the December issue of the Iowa Dental Bulletin, I contributed an article upon the subject, "Study Club Organization," in which I outlined its purposes and methods. I need not repeat these points at this time but wish to say only this in regard to it; Study Clubs should be the starting point of our dental system of post-graduate education. They should be the initiating factor, and the germ of progress engendered in their meetings should find development in higher educational work of the post-graduate college. The Study Club work could be materially helped and advanced by coordination under the direction of a committee in each state society which, in turn, is linked with the superintendent of State Dental Societies of the N. D. A.

In drawing this paper to a close, I wish to leave three pertinent thoughts in your minds.

1. State Societies must recognize the fact that the standard of the profession as a whole is moved forward thru them, and their obligation in meeting the requirements and conditions of today is greater than ever before. Cooperation and coordination are the keys that unlock the door for their success.

2. From the evidence submitted me thru answers to my questionnaire, I believe it important and a desire of the majority that the N.D. A. assume thru some medium as I have suggested, a responsibility of coordinating and standardizing state and district societies.

3. That some method of action be adopted by the N.D. A. that will assist in bringing about a means of establishing post-graduate work upon a real educational basis in our dental colleges with a separate staff of instructors and leading to an advanced degree.

We are all ambitious for success and we are willing to work and learn the things that carry us toward our goal. Continued application is the only way to advance and the possibilities of advancement thru the organized body of which we are a part is unlimited and its importance paramount. Born in obscurity, dentistry has steadily advanced more rapidly than most any other science. It is for the men of today to keep their faces forward and as each individual works for victory for himself, he is constantly helping others toward a higher aim and standard.

Plan for more than you can do, Then do it.

Bite off more than you can chew,

Then chew it.

Hitch your wagon to a star,

Stick in your seat, and there you are.

\section{BIBLIOGRAPHY.}

Dr, Otto U. King, "A State's Society's Aim," N. D. A. Journal, Vol, 3 No. 3, July 1916.

Dr. C. R. Lawrence, "Post-Graduate Dental Meeting," N. D. A. Journal, Vol. 4, No. 5, May 1917.

Dr. E. R. Swank, "Study Club organization," Iowa State Dental Bulletin, December 1918.

Dr. J. V. Conzett, "Study Clubs," N. D. A. Journal, Vol. 6 No. 2, February 1919.

Dr. Otto U. King, "Fourteen Points of Professional Success,” N. D. A. Journal, Vol. 7 No. 7 , July 1919 .

\section{Discussion.}

\section{R. Lawrence, Enid, Oklahoma.}

Dr. Swank's excellent paper brings before us a timely and important subject. There are many things in this paper I should like to discuss in detail, but as 
the chairman of this section has limited me to a very few minutes I must content myself by touching on a very few points and these in a general way.

We are all ready to agree with the essayist that we should have better educated dentists and the one thing we need to consider, in discussing this paper, is the best means to bring this about. There is no doubt that most dental societies are not measuring up to their greatest possibility. The principal mission of the dental society today should be to make better dentists. The masses of the dentists are looking to the dental society for their advancement and the society that is not supplying this need is not, in my opinion, measuring up to its greatest possibilities. I agree with the essayist that much of this inefficiency is due to lack of proper organization and inefficient management. Dr. Swank points out to us that no dental society will ever grow beyond the spirit and aim of its executives, which is certainly very true. It is disappointing to know of the number of dental organizations that move along in the same old channel year after year. What we want, need and must have, if we are to make greater progress, are men for guiding heads who have the inclination and are ready and willing to get behind the screens, pull off their coats and go to work. If necessary we should tear down the whole machinery, put new spokes in the wheels where needed, kick out the men who do not fit into the new order of things and bring out a model that is up-to-date and one that will fill the needs and demands of the times.

We must rise above such things as the selection of officers simply because they have been "honorable members" of this society for 25 years. Too many officers forget to be an honor to their society and only think of the society honoring them. I am an advocate of the general manager plan for state societies, especially those that are attempting anything along what we call post-graduat. iines. This solves some of the inefficiency problems. Many officers, while they are not capable of directing things, do have the ability to select a man who is capable of meeting the requirements. Several state societies are adopting the general manager plan and are paying their manager for his services.

I am in hearty accord with Dr. Swank in his recommendation that the National Dental Association should have an officer or committee such as he suggests. I have advocated this from time to time and I believe such an officer would be of great deal more value than three vice-presidents whose sole duty seems to be (?). This matter might be handled, in so far as talent for our meetings is concerned, on the Chautauqua plan. I am of the opinion that if the National Dental Association does not do this thing, some energetic organizer will do it and put the whole thing on a commercial basis. Anyone who has followed the history of the National Dental Association must recognize the fact that it has not been a leader, not even a directing head in many important affairs to the profession. I say this with all due respect to the good work that is being done at this time, but there are still important duties that should be taken up by this organization. It took the National Dental Association many years to even wake up to the importance of reorganization.

Dr. Swank's finding society membership and attendance, with one exception, I think is approximately correct as it coincides very closely with an investigation conducted by the State Dental Society Officers' section of the National Dental Association a few years ago.

Dr. Swank in different parts of his paper has these things to say:

"The greatest problem of dental societies today lies not so much in finding new operative procedures or new methods of practicing our profession as in keep- 
ing the majority of tite profession abreast of the progress already achieved."

"Only as our dentul societies arrange, plan and execute a program along a teaching line do they live up to and hold the attention of their constituent body."

"The dental society must become a real educational center for the dental practitioner."

I heartily agree with all these statements.

He then writes Article IV, of his conclusions and spoils all his previous arguments along these lines, and I wish to take decided issue with him on this article.

I am a dyed in the wool believer in and an advocate of what is generally called the Post-Graduate Dental Meeting, or "Oklahoma Way." My opinion of this plan and arguments in favor of it are not theoretical but are based upon a very close observation of its practical application.

I am sure Dr. Swank's conclusions in Article IV do not fit present conditions. He wants to start too high on the ladder. We must creep before we walk, and if we can creep along for a few years, giving short post-graduate courses to the masses of the profession at our state meetings, it will not be long until many members of our profession will be walking into the colleges for more extended work.

Much might be said with reference to post-graduate courses by the colleges. This work should be encouraged, but, in my opinion, the colleges at this time will not, for various reasons, make any great success of post-graduate instruction. We have not yet arrived at the point where any great numbers of our profession are going to close their offices for a few weeks at a time, travel long distances at much expense in order to secure post-graduate instruction. So it remains for the dental society to step forward and by cooperative effort, give its members just what they want. Co- operation is the keynote in meeting many a situation that never can or will be met in any other way.

We have a vast amount of dental knowledge and the thing we need most at this time, is better distribution service. The state or large district dental society cannot, in my opinion, be of any greater service to its members than by acting as distributing centers. Why should it be necessary for the dentists of California to travel to Chicago in order to secure professional knowledge some man possesses? Would it not be fär better and cheaper to have the Chicago man go to California and there present his teaching to a much larger number of men?

To meet the situation in our state, the Oklahoma State Dental Society has been bringing a corps of the foremost dental teachers of the country to us each year to conduct an intensive course of study in the different branches of dentistry, which we call the "Class System of PostGraduate Instruction." This plan briefly explained is as follows:

First. The full attendance is divided into classes.

Second. Each class takes up the intensive study of one particular subject for a full week under the direction of a competent teacher.

Third. The instruction for each class consists of lectures and practical demonstrations.

Fourth. A special clinic is conducted by each class and where possible the students are given the privilege of doing some practical work under the supervision of the teacher.

Fifth. No member is permitted to take up the study of more than one subject as the different classes are in session at the same time.

Sixth. Each of our teachers give one or more lectures to the whole society, so that the members of each class are permitted to hear lectures on subjects other than the class in which they are enrolled.

It should not require very much of an 
imagination to see wherein this plan excels. Too much of our teaching at dental meetings is incomplete and leaves only a superficial knowledge. By this plan each member is given the opportunity of laying a broader foundation which insures success later. It is far better for a man to learn to do one thing well than to attempt to do many things and not succeed at any of them.

These meetings in our State have been a decided success and the essayist is very much mistaken when he says, "attention at such meetings cannot be successfully concentrated." The attention is not only concentrated but our membership percentage of attendance is the largest in the society's history. Such meetings as this cost a great deal of money and, consequently, each member in attendance is required to pay a special fee. This, however, is not a stumbling block, for it is just as easy to secure this special fee as it was to secure a very small membership fee a few years ago. At this time no less than fifteen State dental societies have voted to adopt this pla. next year. This is very natural because human nature and dentists are somewhat the same the country over and what is a success in one section is bound to be a success in another, provided the work is carried out along the lines of what ther societies have found out to be a correct principle.

Such meetings are a great stimulus to further study and post-gradute work. To bring the rank and file of our profession in direct touch with our leading teachers for short periods, naturally brings about a desire to follow the writings of these teachers and quite ofter leads to further post-graduate work. I have at different times made an investigation of the number of text books that are sold as a direct result of these meetings and invariably found such sales to be quite large. This plan gives the individual dentist the very best of instruction and will certainly have a tendency to eliminate incompetent teachers and the fakirs.

It is my opinion that the regular broken doses of post-graduate instruction, such as we are giving our members, will be much more effective and reach a far greater number of 'men than the occasional larger doses a few men will take by attending colleges. The one week post-graduate instruction each year, gives a man an opportunity to assimilate and put into practice the things he has learned. It is the constant pounding away that counts in efforts of this kind and not the occasional efforts with long intervals between which is likely to be the case if we depend upon the colleges alone for post-graduate instruction. Not only this, but the association of all our members in one great drive each year carries with it a spirit of the thing that cannot be attained in any other way.

Yes, the possibilities of educating the dentists thru organization are great, provided we make the right application and use of the organizations, but I am of the opinion that this will never be brought about thru the plan suggested by the essayist. (Applause.)

\section{Homer C. Brown, Columbus, Ohio.}

The essayist presents a very important subject for consideration, as there is today, in the dental profession, a greater desire for further knowledge than at any previous time. Arguments have been presented by the essayist in favor of a certain procedure in post-graduate work, but some opposition has been advanced by the first discusser to the plan proposed. However, I believe there may be some unification of the best features of each plan, which will prove beneficial to all concerned.

Personally, I am a firm believer in a progressive and constructive dental organization. A few years ago the membership of the National Dental Association was only six to eight hundred, and in face of this it was a difficult thing to 
reorganize it. I am reminded of one incident in that connection by observing, just in front of me, Dr. H. Clay Hassell, an ex-president of the southern branch of the National Dental Association who, in 1911, invited me to attend their meeting in Atlanta and present a paper on "The Reorganization of the National Dental Association." I was Recording Secretary of the National at that time and will admit that the subject was somewhat drastic for an officer to discuss, especially in the south. Nevertheless, I responded and made some specific recommendations in strict accordance with our present plan of organization. To say the least, the essayist and his recommendations were very generally cussed and discussed, but three years later it was my good fortune, as President of the National, to be invited to attend the final meeting of the southern branch, after it had rendered years of commendable and efficient service in the progress of dentistry in this particular section of the country. I only refer to this because it shows the trend of events during a brief period of three years. In the meantime the National Dental Association had been reorganized, and the first year after this reorganization we had a membership of approximately twelve thousand five hundred, which should fully demonstrate to everyone the need for such a reorganization. This, and its continued growth, have completely justified all effort expended in that much antagonized movement.

One criticism has been made with reference to state societies conducting postgraduate courses, and that is, officers are elected from time to time without any thought of coordinating the activities of their societies. I grant that there is much merit in that criticism and am in favor of officers being chosen who will cooperate in promoting some prearranged program approved by the society. I think, however, that the post-graduate feature of the state society should only be promoted in its fullest sense in organizations with a limited membership, but on the other hand they should be conducted and accepted as a stimulus to individual study and to influence the organizing of local study clubs. Later, a certain percentage will seek increased opportunities in such institutions as seem best equipped to meet their particular requirements.

In my mind there is some question as to what may develop if most of the dental colleges should undertake to conduct post-graduate courses, and it would seem advisable that some plan of supervision or regulation may be undertaken whereby those institutions meeting certain specific requirements could be approved as fully equipped to give post-graduate courses. Then, after obtaining a sufficient number of credits, I think it is perfectly proper that such an institution should grant some supplemental degree, or at least issue an appropriate certificate of the work completed.

We all appreciate that dentistry today is occupying a more favorable and responsible position than it did a few years ago. The fact of the increased status granted by the federal government; the fact that the medical profession is looking to us for more assistance and a closer cooperation than at any previous time, and the further fact that the public is just beginning to recognize the influence of pathological oral conditions upon the general health of the individual, all of which should stimulate us to make the best possible preparation in order that we can render the most efficient service. Therefore, post-graduate work becomes essential and many of the older practitioners will find it necessary to take advantage of this, or some similar method of further education, in order that we may make our full contribution toward solving many of the complicated problems confronting us at this time, as well as those which may become more complex in the future. (Applause.) 


\section{G. Walter Dittmar, Chicago, Ill.}

I want to first compliment the essayist. The paper, it seems to me, is a classic; it is well written, is rich in thought and was well delivered. However, like Dr. Lawrence, I feel that there are some exceptions to be taken. I happened to be a member of the reorganization committee of the Illinois State Dental Society, which was the organization that set into motion the proposition which finally resulted in the reorganization of the National Dental Association. We have the general body and the component societies of these subdivisions are in large cities again subdivided, so we have in operation in the State of Illinois about the plan which was outlined. In Illinois we are placed in a different position; we just happen to be more fortunate than the men down in Oklahoma, Arizona, Florida, Maine or Washington. We have, in Chicago, three large dental educational institutions, consequently our men in Illinois are being fed dentistry so much that many are dyspeptic; it is hard to interest the average dentist; you cannot get him to the meetings, the point I want to make is that the plan of Dr. Lawrence, that has worked so successfully is a very excellent one for the man who happens to be far distant from a center such as I happen to be in; it is indeed an ideal plan for those men. It would, however, not be necessary in Illinois. I do not know that I want to say anything more regarding society work. Being a college man I want to speak from that standpoint. The essayist proposed that the various dental colleges should give post-graduate courses, and further proposed, if I understood him correctly, that there should be extension courses; in other words, that a university having a dental school should organize to the extent of sending some of its faculty out over the state in order to educate the dentists of that state. I will say that that also is in contemplation in our state university; in fact, there is now such a movement on foot. There is another thing I want to mention, and that was brought out very forcibly in the President's address last night. In fact, there has been so much done during the past few years calling people's attention to the needs of dentistry, that we find at the present time not one-tenth enough dentists to properly take care of the mouths of the people. We are raising standards right along. Some colleges giving a four-year course at the present time, are talking five years; in fact, one college has already instituted a five-year course. How are we going to supply the demand? The demand is getting greater every minute. The time will come, possibly, when it may adjust itself, but in the meantime the masses will suffer. I wonder whether we ought not go a little slower? In Illinois this last year during the epidemic of influenza we found a great dearth of nurses; the requirements for nurses were raised so that the product was naturally small, and as a consequence the whole state suffered. There was a bill introduced in the last Illinois legislature for education of practical nurses; and unless we take heed the time will come when there will be a similar demand for practical dentists. (Applause.)

E. R. Swank: There were two things I had in mind in presenting this paper. One was to outline the necessity for the standardization of state society work under the coordinating direction of the $\mathrm{Na}$ tional Dental Association. The second was to distinguish between the short post-graduate work as conducted in Columbia, and the more intensive postgraduate work with definite requirements leading to an advanced degree. I think Dr. Lawrence said they had less than three hundred members in Oklahoma. From the information I received they had three hundred and twenty-five with an attendance at their state meeting of 160 . 
Dr. Lawrence: You have this year's membership, not last year.

Dr. Swank: Well, at two hundred, you can divide that into smaller classes, twenty-five or thirty, and that is very practical; with that number you can take the work and carry it out very successfully, but in larger societies it is not so successful. I wanted to distinguish between a short course of three or four days, or a week's duration, and a course covering the theoretical and the practical work of a subject that will lead to a definite degree, that requires attendance or certain credits for its completion in the same manner as is required in postgraduate colleges for advanced degrees in other fields of education.

There was one question that Dr. Dittmar brought up on extension courses. I did not mean to take the work to the dentist, as he explained, but I mean to establish the post-graduate course in certain of our large and centrally located universities, and have the dentist go there for special courses and when enough credits are earned, proper recognition is given him. However, I believe that arrangements could be made whereby certain teachers or extension professors would become available for district Society programs and to assist in special research work of Study Clubs, such arrangements being made by the Superintendent of District Societies of either the State Society or the N. D. A. But the spirit of research engendered in study clubs and the smaller post-graduate courses, should be carried further by study in the larger institutions, and proper credit being given for one or two weeks' study and a degree for perhaps two years' special study. Attention at state society meetings giving so-called post-graduate course cannot be concentrated in a manner that it can be in our universities. I know that to be a fact from the experience I have had with the Iowa State Dental Society. We have an annual attendance at our state meeting of four times the Oklahoma attendance and I do not see how eight hundred members can be successfully divided into classes for practical instruction in any one branch of our professional work, without having twenty-five or thirty different classes and teachers in session at the same time. I am not trying to disparage the Oklahoma way for Oklahoma, but for the larger and the majority of societies, I am of the opinion the Oklahoma way is not applicable.

I wish to thank those men who answered this questionnaire for me and also the men who so kindly honored me by discussing this paper. I thank you. (Applause.)

The Chairman: Because of the lack of time and the importance of the paper we have following this one, this discussion will not be thrown upon the floor. If you have one or two pointed, direct questions to ask I will give you this opportunity at this moment.

Dr. Park, Detroit, Mich.: I would like to ask Dr. Lawrence if the scheme for intensive study as applied in Columbus, is equally applicable to a large society such as they have in New York or Ohio or Illinois?

Dr. Lawrence: I should answer that in this way: I think in a modified form; I do not think it would be applicable as a whole. The classes are limited to about twenty or thirty men. That could be handled by dividing your state societies into sections. 